\title{
Study of the Relationship Between Life Quality and Occupational Accidents in Wood Industry
}

\author{
Mohammad Agh ${ }^{1} ; \operatorname{Ramazan~Mirzaei~}^{2, *} ;$ Mahdi Mohammadi $^{2}$ \\ ${ }^{1}$ Department of Environmental Science, Science and Research Branch, Islamic Azad University, Zahedan, IR Iran \\ ${ }^{2}$ Health Promotion Research Center, Zahedan University of Medical Sciences, Zahedan, IR Iran \\ ${ }^{*}$ Corresponding author: Ramazan Mirzaei, Health Promotion Research Center, Zahedan University of Medical Sciences, Zahedan, IR Iran. Tel: +98-5413425839, Fax: +98-5413425838, \\ E-mail:rammir277@yahoo.com
}

Received: July 31, 2013; Revised: October 20, 2013; Accepted: October 20, 2013

\begin{abstract}
Background: Occupational accidents are a major problem in industries and work environments.
Objectives: This study aimed to study the relationship between workers' life quality and occupational accidents.

Materials and Methods: This historical cohort study was conducted on 114 wood industry workers (living in the North of Iran) involved in a job related accident over the past 10 years. Among those with no job-related accidents, 118 workers were randomly selected so that both groups were comparable in terms of age, work history and type of job. Standardized form of SF36 for the Iranian culture was used to determine the life quality of workers. Furthermore, demographic factors were added to the SF36 questionnaire. Data were analyzed with the two independent samples t-test, Mann-Whitney and Chi-square test using the SPSS 19 software.

Results: In this survey average scores for different aspects of life quality in the case group and control group were as follows, physical functioning $67.23 \pm 2.413$ and $81.99 \pm 2.193$ and mental health $59.12 \pm 16.76$ and $71.52 \pm 18.14$, respectively. There was an obvious and significant difference $(\mathrm{P}<0.05)$ between physical and mental health of injured workers' life quality compared to the uninjured group (control group). The results showed that all eight domains of life quality except limitations due to emotional problems were significantly different between the study and control groups.

Conclusions: The results of this study show that unsafe work condition and high-risk behavior of workers lead to job-related accidents which affect worker's health and their life quality.
\end{abstract}

Keywords: Quality of Life; Accidents, Occupational; Safety; Industry, Mental Health, Physical

\section{Background}

Work has always been a part of people's lives and is considered as a value and everyone believes that working can be a path for acquisition of financial status and reputation, respect and economic development. Each person, for living, chooses a job, which can have potential dangers and may injure the person. Occupational accidents are among major problems and should be the main concern in work environments although data on occupational accidents are not available from all countries around the world. In 1994, the global average estimated fatal occupational accident rate was 14.0 per 100,000 workers (1). Occupational accidents are the third leading cause of deaths worldwide and they have been recognized as one of the most important hygienic, social and economic hazards in both developing and industrial countries (2). According to the international labour organization (ILO) report, laborers experience about 270 million injuries and two million deaths each year in the world (3). The fatality rate of accidents in various countries was different during 2009; workplace fatality rate for Alaska was 5.6/100,000 workers and for the whole world this was 14.0 per $100,000(1,4)$. Based on an investigation of ten years of occupational injuries in Korea from 2001 to 2010, the fatalities of construction, forest, agriculture, and service had an increasing trend and nonfatal occupational injuries of the manufacturing sector were higher than those of other sectors in every year but fatal occupational injuries of construction workers were higher than that of other sectors (5).

Since work-related incidents can be potentially preventable, incidents are commonly due to carelessness, injustice and not obeying the rules (6). In order to sustain and promote employee's health in a population, the first step is to prevent job accidents by identifying sources of hazards in work environments. The most significant causes of incidents are individual elements such as fatigue, having

Implication for health policy/practice/research/medical education:

This study was carried out with the purpose of determining the relationship between life quality and accidents from doing labor at one of the wood industries. Reading this article is recommended to specialists in the field of occupational and environmental health, health policy makers, industrial managers and workers.

Copyright (c) 2014, Health Promotion Research Center. This is an open-access article distributed under the terms of the Creative Commons Attribution License, which permits unrestricted use, distribution, and reproduction in any medium, provided the original work is properly cited. 
Agh M et al.

multiple jobs and family problems (7). Most job incidents result in debility, lower income and reduced life quality of labors as well as lower production rate and benefits of industries (8). The World Health Organization (WHO) has defined life quality as people's understanding of their positions in life considering their culture and value system, goals, expectations, standards and their priorities. Therefore, this is completely a mental issue and cannot be judged by others and is based on people's understanding of different aspects of life (9). While abundant is recognized about the dispersal of occupational injury to various job and employment factors, noticeably less is identified about other risk factors, particularly those concerning psychosocial and organizational factors. The results Smith et al. were showed, race, occupational category, and work-family interference as risk factors, and safety climate and organizational effectiveness as protective factors for occupational injury (10). Incidents in every form and level could impose lots of economical and social problems on the society and increase restrictions. Nonetheless, based on the results of different studies, injuries caused by events can influence life, body and soul of the injured individual and even their family members (11). The short from 36 (SF36) is the most used tool for the determination of life quality (12-14).

\section{Objectives}

The present study aimed to investigate the relationship between worker's life quality and occupational accidents in a Northern wood industry company, so that by recognition and understanding of different aspects of an injured person's life quality, a step can be taken in order to improve life quality related to employer's health.

\section{Materials and Methods}

This historical cohort study was conducted in a wood industry company run by 300 employees located in the North of Iran. The study group included all the workers (116 individuals), injured in a job incident and registered in the company clinic for medical care services during the last 10 years. All information related to the incident and injury was recorded in the clinic files. The control group included 118 workers selected randomly among all workers with no occupational accidents. Both groups were matched in terms of age, work history and type of job. As chronic diseases affect life quality, if workers or their family members had chronic diseases such as diabetes, cancer, heart disease, kidney or respiratory failure, multiple sclerosis skeleton muscle disorders and addiction to narcotic drugs, they were excluded from the study $(7,8)$. All the mentioned information was provided from medical files of employees. Data collection tool was a questionnaire consisting of two parts; demographic characteristics and life quality. The first part included the employee's information such as age, job history, marital status, education level and job type. For the study group, more questions about the time period needed for rest after the injury, time period since the incident, type and consequences of the incident and injured organs were included. In the second part, the short form of the SF-36 questionnaire was translated in to Persian and was used to assess life quality of employees. Validity and reliability of the translated version has been approved in a previous study (15). The SF-36 consists of 36 questions so that 35 questions evaluate eight domains of life quality; physical function, physical roles limitation, bodily pain, general health, vitality, social function, emotional roles limitation and mental health. Also, an additional question assesses the individual's health status over a one-year period. Each question is scored between 0 and 100 for poor to excellent items, respectively and each domain includes 2 - 8 questions. Quality of each domain is evaluated by taking the mean scores given to questions related to that domain. Therefore, domains are given a score between 0 and 100 with a higher score indicating higher quality for that domain. Physical health is defined by averaging the scores of the first four domains. The last four aspects define mental health. All illiterate workers were interviewed by one interviewer who filled out the questionnaire simultaneously. All other workers completed the questionnaire by themselves. Data were analyzed by the Spearman correlation, Mann-Whitney and Kruskal-Wallis tests using the SPSS 19 software with 5\% significance level.

\section{Results}

Mean of age of study and control groups was 35.4 and 34.7 , respectively with no significant difference $(P=0.537)$ between them. There was also no significant difference in mean work history between study (10.21) and control (8.92) groups $(\mathrm{P}=0.165) .83 .3 \%$ and $76.3 \%$ of workers with and without job incident history were married. More than two thirds of workers in both groups were either high school or university graduates. Furthermore, about $51 \%$ of workers in both groups worked with mechanical equipment. The two groups were not significantly different regarding education level $(\mathrm{P}=0.102)$ and type of job $(\mathrm{P}=0.804)$ (Table 1$)$.

Falling objects (24.6\%), car crash (18.4\%), working with mechanical equipment (16.7\%), worker fall (15.8\%), pours (12.3\%) and electricity (7\%) were causes of job incidents. Fractures (28.9\%), contusions (26.3\%), cuts (17.5\%), burns (7.9\%), dislocations (5.3\%) and amputations (3.5\%) were the consequences of job incidents. The most frequent incidents affected hands (38.6\%) followed by head and face (21.9\%), legs (19.3\%) and the whole body (19.3\%) (Table 2).

Statistical analyses showed that the average scores of different aspects of life quality were as follows; physical function and role limitation because of physical 
Agh M et al.

problems was $67.23 \pm 2.4$ and $56.35 \pm 35.94$ for the case group and $81.99 \pm 2.19$ and $75.97 \pm 33.45$ for the witness group, bodily pain and general health was $50.43 \pm 26.25$ and $54.82 \pm 16.13$ for the case group and $70.72 \pm 26.01$ and $68.38 \pm 17.22$ for the witness group, vitality and social function was $54.82 \pm 15.11$ and $41.1 \pm 14.47$ for the case group and $68.22 \pm 17.26$ and $50.85 \pm 14.81$ for the witness group, role limitation because of spiritual problems and mental health was $61.98 \pm 37.3$ and $59.12 \pm 16.78$ for the case group and $71.52 \pm 18.14$ and $68.36 \pm 37.7$ for the for witness group. All eight domains of life quality except emotional roles limitation were significantly different between the study and control groups. The highest mean score belonged to physical function for both study group $(67.2 \pm 2.4)$ and control group $(82.0 \pm 2.2)$. The lowest mean score belonged to social function for both study group (41.1 \pm 14.5$)$ and control group (50.8 \pm 14.8). Physical roles limitation had the greatest difference between the study (56.4 \pm 35.9$)$ and control (76.0 \pm 33.4) groups (Table 3 ).

\begin{tabular}{llll}
\hline \multicolumn{1}{l}{ Table 1. Team Characteristics of Case Group and Control Group Samples } & & \\
\hline Variable & Frequency, No. (\%), n= 114 & Frequency, No. (\%), n= 118 & P value \\
\hline Level of education & & & 0.102 \\
\hline Less than 5 years & $14(12.28)$ & $14(11.86)$ & $14(11.86)$ \\
\hline Guidance school knowledge & $22(19.29)$ & $38(32.2)$ & 0.804 \\
\hline Diploma & $43(37.71)$ & $52(44.06)$ & \\
\hline Above diploma & $35(30.7)$ & $18(15.25)$ & $12(10.17)$ \\
Type of Occupation & & $24(20.34)$ \\
\hline Technical & $18(15.52)$ & $22(18.64)$ \\
\hline Driver & $8(7.02)$ & $10(8.47)$ \\
\hline Services & $24(21.05)$ & $9(7.63)$ \\
\hline Supervision & $22(1930)$ & $9(7.63)$ \\
\hline Chopper & $10(8.77)$ & $14(11.86)$ \\
\hline Grinder and dryer & $9(7.89)$ & \\
\hline Press and sandpapering & $9(7.89)$ & $14(12.28)$ & \\
\hline Wrapping & & \\
\hline
\end{tabular}

Table 2. Distribution of Workplace Accidents in Terms of Organ Damage

\begin{tabular}{ll}
\hline Variable & Frequency, No. $(\%)$ \\
\hline Injured Organ & \\
Head and face & $25(21.9)$ \\
Hands & $44(38.6)$ \\
Feet & $22(19.3)$ \\
Whole body & $22(19.3)$ \\
\hline
\end{tabular}

Table 3. Comparison of the Average Scores of Octad Aspects of Life Quality for Case and Control Groups

\begin{tabular}{llll}
\hline Aspects of Life Quality & Case, Mean \pm SD, $\mathbf{n}=\mathbf{1 1 4}$ & Control Group, Mean \pm SD, $\mathbf{n}=\mathbf{1 1 4}$ & P value \\
\hline Physical function & $67.23 \pm 2.413$ & $81.99 \pm 2.193$ & $<0.001$ \\
Role limitation due to physical problems & $56.35 \pm 35.94$ & $75.97 \pm 33.45$ & $<0.001$ \\
\hline Physical/body pain & $50.43 \pm 26.25$ & $70.7 \pm 26.01$ & $<0.001$ \\
General health & $54.82 \pm 16.129$ & $68.38 \pm 17.22$ & $<0.001$ \\
Vitality & $54.82 \pm 15.109$ & $68.22 \pm 17.265$ & $<0.001$ \\
Social function & $41.11 \pm 14.47$ & $50.85 \pm 14.81$ & $<0.001$ \\
Role limitation due to mental problems & $61.98 \pm 37.33$ & $68.36 \pm 37.70$ & 0.133 \\
Mental health & $59.12 \pm 16.76$ & $71.52 \pm 18.14$ & $<0.001$ \\
\hline
\end{tabular}




\section{Discussion}

The results show that there is a great difference between average scores of life quality of injured $(50.43 \pm 26.25)$ and uninjured individuals $(70.72 \pm 26.01)$ in terms of bodily pain, which is similar to the results reported by Monteiro et al. on injured people in three hospitals of Brazil during the year 2009 (16). Pain and suffering which varies from weak specter, local discomfort to the malaise could be one of the consequences of an accident, required to be taken into consideration. There is an obvious difference between average scores of role limitation because of physical problems between the case group $(56.35 \pm 35.94)$ and the witness group $(75.97 \pm 33.45)(\mathrm{P}<0.05)$, which is similar to the findings of Nobel et al. (17). One of the main reasons is pain with nervy resources while doing physical activities. On the other hand, it is expected that an injured person who is suffering from physical pain and role limitation because of physical problems will not be happy and will be less cheerful; in some cases they may have developed depression. The results of the study by Peele et al. showed that depression symptoms in injured people are more than uninjured individuals (18). Moreover, this study showed that there is a meaningful relationship between short mental health measurements and marital status $(\mathrm{P}<0.05)$; in a way that mental health in married people is better than bachelors; but there is no meaningful relationship between short physical measurement and marital status ( $\mathrm{P}>$ 0.05). The study by Nobel et al. on electric shocks with high voltage showed that pain caused by incidents had an influence on sexual relationships of couples and had decreased the life quality of the injured individual (17). The difference between average scores of physical and mental health's aspects of injured people's life quality and uninjured individuals was meaningful $(\mathrm{P}<0.05)$. The results of the study demonstrated that preventive rules for the development of aspects linked to the physical domain are essential both in the workplace and outside the work environment (19). A survey on the occurrence of occupational accidents and health-related quality of life of hospital workers using the SF-36 questionnaire revealed that there was no significant differences relationship between injury and healthrelated quality of life although there were high average values in most of the analyzed domains, and the lowest score observed was vitality and bodily pain (17). Bad and unsecure job conditions in the majority of wood industries will affect the frequency and violence of occupational accidents. Hence, the big challenge now is how to develop strategies in order to improve job conditions. The results of this study prove that unsecure conditions and incidents caused by labor, can have an effect on the life quality of people and reduce the health of the society. Hence, more research by designing special tools in order to understand the life quality of injured people under the influence of occupational accidents appears to be vital and necessary.

\section{Acknowledgements}

The authors would like to thank all the employees of the publishing industry and everyone else who participated in this study.

\section{Authors' Contribution}

The overall implementation of this study including design, data management and analysis, and manuscript preparation were the results of joint efforts by multiple individuals who are listed as co-authors of this paper. All authors have made extensive contribution into the review and finalization of this manuscript.

\section{Financial Disclosure}

There are no conflicts of interest.

\section{Funding/Support}

The project was supported financially by Health, Safety and Environment Department of Islamic Azad University, Science and Research Branch.

\section{References}

1. Takala J. Global estimates of fatal occupational accidents. Epidemiology. 1999;10(5):640-6.

2. Dorman P. The economics of safety, health, and wellbeing at work: an overview. 2000; Available from: http://oit.org/wcmsp5/groups public/---ed_protect/---protrav/---safework/documents/publication/wcms_110382.pdf.

3. DeLeire T, Levy H. Gender, occupation choice and the risk of death at work. Cambridge, the USA: National Bureau of Economic Research; 2001.

4. Lincoln JM, O'Connor MB, Retzer KD, Hill RD, Teske TD, Woodward CC, et al. Occupational Fatalities in Alaska: Two Decades of Progress, 1990-1999 and 2000-2009. J Safety Res. 2013;44:105-10.

5. Rhee KY, Choe SW, Kim YS, Koo KH. The trend of occupational injuries in Korea from 2001 to 2010. SafHealth Work. 2013;4(1):63-70.

6. Centers for Disease Control Prevention. Nonfatal occupational injuries and illnesses-United States, 2004. MMWR Morb Mortal Wkly Rep. 2007;56(16):393-7.

7. Ghods A, Alhani F, Monireh A, Kahoie M. [Epidemiology of occupational accidents in Semnan (2002-2006)].J semnan Med Sci Uni. 2009;10(2).

8. Breslin FC, Smith P. Trial by fire: a multivariate examination of the relation between job tenure and work injuries. Occup Environ Med. 2006;63(1):27-32.

9. Bonomi AE, Patrick DL, Bushnell DM, Martin M. Validation of the United States' version of the World Health Organization Quality of Life (WHOQOL) instrument. J Clin Epidemiol. 2000;53(1):1-12.

10. Smith TD, DeJoy DM. Occupational injury in America: An analysis of risk factors using data from the General Social Survey (GSS). Safety Res. 2012;43(1):67-74.

11. Snashall D. Occupational health in the construction industry. Scand J Work Environ Health. 2005;31 Suppl 2:5-10.

12. Gamsiz Bilgin N, Mert E, Sezgin M. Evaluation of the effects of disabilities due to traffic accidents on the quality of life using SF-36 health survey. Acta Orthop Traumatol Turc. 2012;46(3):168-73.

13. Taft C, Karlsson J, Sullivan M. Do SF-36 summary component scores accurately summarize subscale scores? Qual Life Res. 2001;10(5):395-404.

14. Demiral Y, Ergor G, Unal B, Semin S, Akvardar Y, Kivircik B, et al Normative data and discriminative properties of short form 
Agh M et al.

36 (SF-36) in Turkish urban population. BMC Public Health. 2006;6:247.

15. Montazri A, Gashtasebi A, Vahdani M. [Reliability and validity of Persian questionnaire SF-36]. Payesh J. 2006;5:49-56.

16. Monteiro CM, Benatti MC, Rodrigues RC. Occupational accidents and health-related quality of life: a study in three hospitals. Rev Lat Am Enfermagem. 2009;17(1):101-7.
17. Noble J, Gomez M, Fish JS. Quality of life and return to work following electrical burns. Burns. 2006;32(2):159-64.

18. Peele PB, Tollerud DJ. Depression and occupational injury: results of a pilot investigation.J Occup Environ Med. 2005;47(4):424-7.

19. da Costa CS, de Freitas EG, Mendonca LC, Alem ME, Coury HJ. [Work ability and quality of life of Brazilian industrial workers]. Cien Saude Colet. 2012;17(6):1635-42. 